\title{
5
}

\section{Classroom ethos and the concerns of the teacher}

\author{
John Olson
}

Queen's University

Ontario, Canada

\begin{abstract}
It is useful to think of information technology as representing a cluster of educational ideas which may or may not challenge existing practices. How teachers respond to those challenges constitutes the potential for improvement.

Superficial accommodation to technology is everywhere evident and reported, but what are the deeper implications for teachers of particular challenges posed by IT to how subjects are construed and taught? This paper will consider research which illuminates increasingly deeper concerns of teachers about IT and the classroom ethos.
\end{abstract}

Keywords: classroom practice, curriculum development, innovation, integration, pedagogy

\section{INTRODUCTION}

In this paper three major aspects of integration will be considered. First, I will consider IT and the process of change; for example, integrating IT into classroom routines, rewriting curriculum materials, researching software, restructuring the classroom layout. This leads secondly, to integrating with and reflecting on the pedagogical theory underlying the IT "package" or cluster of ideas; the role of teacher in using IT, the nature of 
student activity, the nature of subject matter knowledge, the content of the activity, the connection of classroom work to the world outside. Finally, I will consider the implications of teacher concerns for research and development of IT.

\section{IT AND THE PROCESS OF CHANGE}

Watson [1] notes that where computers are located is an important issue for integration. She says that teachers having to rely on specialist computer rooms may be inhibited in integrating computers. She locates the problem in the difficulty of access and in the different ways of working which computer managers and teachers might have. These factors can create a distance between teacher and class. She says there is also loss of control which can undermine confidence. She concludes that micros should be located in subject-based rooms which provide a supportive environment for teachers, and that successful integration depends on such an environment. She refers to other work which supports this idea: "unless we consider more carefully the nature ... (of) classrooms themselves we cannot expect that our software development and in-service activities will have any more impact in the future than they have in the past" p. 36. The computer is one tool amongst others found in classrooms, not a classroom in itself. Watson is urging that the computer be seen as part of a complex ecology of resources which lie at hand for teachers in tacit ways.

Tanner [2], reporting on a study of the implementation of IT in mathematics education, found that access to computers is a major problem for teachers. The access problem could be alleviated if computer studies courses were done away with, Tanner recommends. He suggests that "activities which develop IT skills through subject teaching should be built into the scheme of work of all subject areas" p. 148. He suggests that computers studies teachers become advisors to those using computers in subject teaching.

Van den Akker et al [3] note the extensive literature on implementation which points to the need for a developmental approach to change. They call such an approach to integration of computers "an infusion approach". It is a staged approach in which early success is vital if implementation "fidelity" is to be achieved. Early success, they believe, can be achieved if the materials reflect an awareness of the problems teachers face in implementation of innovations. Problems they point to are: lack of time, background knowledge and appropriate "didactical role" p.73, and 
restricted sense of the learning potential of the material. An initial study, in which materials were designed with these problems in mind, suggested that high fidelity implementation could be achieved when teachers had initial success with materials.

Voogt [4], a colleague of van Akker, notes that, even though IEA data for the Netherlands suggest increased computer use in science education, data about the intensity of use are not available, and more needs to be known about the implementation process. She points out that even though concrete guidelines for use of software are provided teachers do not necessarily act in accordance with those guidelines.

In her research she found that teachers did not use the teacher guide designed to accompany a science programme. Even though the 'operational manual' was placed in their hands, teachers, used the software according to their own planning. As she notes, "Secondary science teachers already have their own subject matter and pedagogical knowledge. In their perception, therefore, they probably felt less of a need for special support" p. 144. However, she suggests that teachers may not properly exploit the curriculum potential of the software through failing to "understand it" .

Papert [5] also addresses the role of teachers in change. Like Van Akker et al he sees changes as a process of overcoming obstacles. The obstacle that Papert had addressed in the past was the teacher. He now sees the school organization as the obstacle, and teacher the victim. Unlike Akker et al, he does not think that changes in school management can lead to realizing the potential of computers: "School's hierarchical organization is intimately tied to its view of education, and in particular to its commitment to hierarchical ways of thinking about knowledge itself" p. 61.

Eraut [6] summarizes research on implementation problems. He says there are close parallels between IT in education and earlier innovations on the issue of clarity of purpose. He notes that teachers often have real doubts about the extent to which pupils will benefit from innovations. Even if teachers do incorporate computers in their teaching, Eraut notes, they reach only a certain level of use. To go beyond that level, help in reflecting on the process is needed if computers are to transform the curriculum. The assumption is that computers have transformative potential.

Miller and Olson [7] take issue with this idea. Based on their review of the implementation literature and their own research, they conclude that, on the whole, computers amplify rather than transform practice. They note "Expert systems, virtuality and hypermedia are new 


\section{Integrating information technology into education}

technological areas and the object of interest of futurists, however, those educators who make the best use of these advancements may be those who look backward -- or at least look around -- before leaping ahead" p. 138. In their research they document instances where pre-existing innovative practices are amplified by computers, but where traditional practices are not transformed by using computers.

The process of change thus involves the interaction between new technologies and pre-existing practices, as we have seen. The second aspect of integration concerns reflective practice.

\section{IT AND REFLECTIVE PRACTICE}

Ragsdale [8] reviews research on classroom use of computers. He notes that "In classrooms, it seemed particularly difficult to make the use of computers part of the classroom while preserving the teacher's style" $p$. 682. Teachers appear to be less critical about and demanding of student performance when at the computer. He notes that teachers appear uncritical in their assessment of how their students are using computers. Students are given approval for using computers in trivial ways; approval that they would not receive were they using other learning tools. $\mathrm{He}$ draws a distinction between using computer tools and applying them. Application, in his view, means using computers to discover relationships - to use them to see things in new ways. Doing this depends on a culture of inquiry already existing in the classroom. Such a culture, he says, "ultimately depends on relationships between people" p. 683. He reiterates the concern about the classroom as a context in which computers are used and the importance of that context for achieving IT potentials.

Upitis [9] points out the danger of contrived learning, in which uses of technology are "contrived by teachers in order to somehow make use of available technology" p. 233. Lack of easy access that Watson referred to, may itself give rise to contrived teaching, as a teacher coping strategy. Upitis says that, for there to be reality in electronic communication there has to be a feeling that students are dealing with real issues: "Electronic mail systems are best used when there is a need to learn the tool." Implicit in this idea that the tool is at hand. So the issue of contrived learning, that is to say the quality of work, is a function of both needing the tool and also having it, and having it means having it "to hand".

Brown [10] reviews research on the implementation process in relation to an evaluation of the UK Information Technology Teacher Training Development Programme (ITTTDP). He argues that teacher concerns 
about IT are evolving rapidly and that these concerns are the subject of reflection and clarification. The need for opportunities for teacher reflection was stressed. The teacher training material developed by the ITTTDP asked teachers to reflect on the learning outcomes supposedly enhanced by the use of IT. In this way the concern about trivial adoption raised by Ragsdale was addressed. Brown also points to the importance of the overall context for learning when assessing the potential of IT. Brown notes that IT can be a stimulation for change "opening up the possibility of transforming aspects of the teaching and learning environment" p. 149. He points to the speed at which results can be generated, freeing up time for discussion and thus deeper understanding. How the tool influences the teaching is, of course, an ongoing issue. Teachers will need to be able to lead effective discussions if this promise is to materialize.

The Council of Europe report Education and the Information Society, edited by Eraut [6], has a chapter on approaches to implementation in different member countries. The report notes that "Both the teacher and the technology have to adapt to each other" p. 63. Olson [11] makes the same point: "The ideas built into software ... can give rise to more intelligent form of teacher-student relationship, but only if software designs are based on an understanding of school life" p. 123. Watson [12], for example, sees teachers as key members of software development teams.

\section{ISSUES FOR DEVELOPMENT OF IT IN EDUCATION}

Such research raises questions about the risks teachers run in extending their ways of teaching to the edge of their comfort zone. These risks involve fundamental issues for teachers, because as Olson [11] states, they are interlinked with the way they are perceived by their students, parents, and administrators and with their own self-concept as teachers.

At the heart of teacher concerns is the maintenance of a certain ethos in the classroom. Those who design software need to do so keeping in mind the concerns of teachers. To better understand integration of IT it is useful to think in terms of two dimensions of change - the instrumental and expressive dimension, and the accommodation-assimilation dimension.

Instrumental actions are meant to achieve certain outcomes; they are intended to be causal. Expressive actions are meant to make statements about what things mean; such actions express values. Teacher use of IT is both instrumental and expressive, and the expressive use of IT often 
precedes the instrumental and may be at odds with it. The use of this distinction is necessary in order to understand why teachers are willing to make the often heavy adjustments needed to achieve even minimal integration of IT in the classroom, and to appreciate the satisfaction and frustration they experience in this process.

Accommodation and assimilation refer to the demands made on teachers by integration. There are the practical problems of accommodating computers into classroom routines. Considerable research on integration addresses such problems. But then there is the process of reflecting on these changes; the process of assimilating the new arrangements within the schemes teachers have for teaching and learning. Accommodating IT challenges those schema. These two dimensions give rise to the ethos of the classroom.

Why is it important for IT designers and managers to consider the ethos of the classroom: that is to appreciate the purpose and methods of those who are attempting to integrate IT in their classrooms? Why is it important for software designers to make explicit their ideas and show how they belong in schools? Teachers can learn much from the ideas of software innovators. Linking teachers and innovators together in innovation takes change as process of dialogue rather than one of implementation. Without this process software development will not lead to a better ethos in schools.

\section{CONCLUSION}

The research I have reviewed suggests that computers in the classroom have many potentials. They perform complex transformations of information rapidly and offer multiple representations of information. They let students probe the systems in order to understand their structure and help them to get to the bottom of things. They form bridges between learning different but related things.

Computers may also be important because they help teachers confront their experience - to make sense of it and thus become aware of the value of what they do. Change is a process of reassigning value to practice as well as actually adopting new practices.

Similarly, it is not only the cognitive capacity of students that is at issue when they tackle problems posed to them by computer programs. They are being asked to see the world in new ways, to value things differently. How they do this depends on prior experience. As outsiders we need to know the network of "ideas" which teachers and students bring 
to their practices. We need to know much more about the nature of existing practices in schools as a context for understanding how IT is integrated. Change, as has been said already, is not just a matter of adopting new technologies - of being innovative - it is coming to teach and learn in new and more productive ways, and this involves the challenge to reflect on practice that IT represents. Such a challenge is the great potential of IT.

\section{REFERENCES}

1. Watson, D. (1990) The classroom versus the computer room. In:

M. Kibby (Ed.), Computer assisted learning. Oxford: Pergamon.

2. Tanner, H. (1992) Developing the use of IT within mathematics through action research. In M. Kibby and J. Hartley (Eds.), Computer Assisted Learning, Oxford: Pergamon Press.

3. van den Akker, J., Keursten, P., \& Plomp, T. (1992) The integration of computer use in education. International Journal of Educational Research, 17 (1), 65-75.

4. Voogt, J. (1993) Courseware for an inquiry-based science curriculum. The Hague: CIP Publishers.

5. Papert, S. (1992) The children's machine. New York: Basic Books.

6. Eraut, M. (1991) The information society: a challenge for education policies? In: M. Eraut (Ed.), Education and the information society. London: Cassell.

7. Miller, L., \& Olson, J. (1994) Putting the computer in its place: A study of teaching with technology. Journal of Curriculum Studies, 26, 121-141.

8. Ragsdale, R. (1992) Making computer tools effective in classrooms. Proceedings of the Ninth International Conference on Technology Education. Austin, TX: University of Texas.

9. Upitis, R. (1990) Real and contrived uses of electronic mail in elementary schools. In M. Kibby (Ed.), Computer assisted learning. Oxford: Pergamon Press.

10. Brown, A. (1994) Processes to support the use of information technology to enhance learning. Computers and Education, 22, 145-154. 
11. Olson, J. (1992) Trojan horse or teacher's pet? In: Computers and the teacher's influence. International Journal of Educational Research, 17 (1), 77-84.

12. Watson, D. (1987) Developing CAL. Computers in the curriculum. London: Harper and Row.

13. Olson, J. (1988) Schools/Microworlds, Computers and the culture of the classroom. Oxford: Pergamon Press.

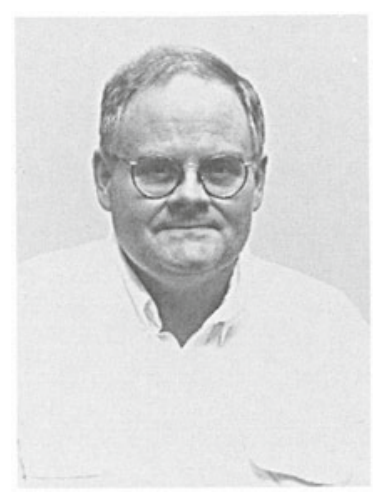

John Olson works with pre-service teachers in science education and does research and graduate work in the field of curriculum change. $\mathrm{He}$ is particularly interested in understanding the teacher's point of view in the innovation process. Over the last 10 years he has conducted a number of research projects on the integration of computers in the classroom. His recent book Understanding Teaching is mostly based on that research. 